\title{
COMUNICADOS
}

\section{Scytalidium lignicola em mandioca: ocorrência no Estado do Maranhão e reação de cultivares ao patógeno}

\author{
Ilka Márcia Ribeiro de Souza Serra ${ }^{1}$, Gilson Soares da Silva ${ }^{1}$, Fagner Silva Nascimento ${ }^{1}$, Luiz Kleber Ferreira Lima ${ }^{1}$
}

${ }^{1}$ Universidade Estadual do Maranhão, Departamento de Fitotecnia e Fitossanidade / Núcleo de Biotecnologia Agronômica, CEP 65041-970, São Luis/MA.

Autor para correspondência: Ilka Márcia Ribeiro de Souza Serra ( ilka.tt@gmail.com)

Data de chegada: 31/10/2008. Aceito para publicação em: 15/06/2009.

A podridão radicular, causada principalmente, por Phytophthora sp. e Fusarium sp. é um dos fatores limitantes da produção de mandioca em algumas áreas da Região Norte e Nordeste. A doença é particularmente importante nos ecossistemas de Várzea e de Terra Firme dos Estados do Pará, Amazonas e Amapá. Estima-se, na Região Amazônica, perdas superiores a $50 \%$ na Várzea, podendo atingir até 30\% em Terra Firme (Mattos et al., Sistemas de Produção, CNPMF, n.13, 2003). Em alguns casos, têm-se observado prejuízos totais, principalmente em plantios conduzidos em áreas constituídas de solos compactados e sujeitos a constantes encharcamentos. O fungo Scytalidium lignicola Pesante tem sido descrito também como um importante patógeno na cultura da mandioca causando a podridão negra em raízes e caule. A presença deste patógeno no Brasil foi verificada pela primeira vez no estado de Pernambuco e, em seguida, nos estados do Pará e de Alagoas (Laranjeira et al., Fitopatol. Bras. 19:466. 1994; Poltronieri et al., Fitopatol. Bras. 23:411. 1998; Muniz et al., Summa Phytopath. 25:156. 1999). Os objetivos do presente trabalho foram relatar a ocorrência da podridão negra em raízes de mandioca no estado do Maranhão e avaliar a reação de cultivares ao patógeno. O isolamento do fungo foi feito em meio de cultura BDA, a partir de raízes com sintomas de podridão (Figura 1A), provenientes de Brejo-MA. Testes de patogenicidade foram realizados em raízes de mandioca cv. Tatajuba em condições de laboratório à temperatura de $25^{\circ} \mathrm{C}$. A reação de resistência das cultivares se deu com a inoculação do fungo em dez cultivares de mandioca (Anajazinho, Anajá da folha amarela, Branquinha, Cigana, Folha de mamão, Olho verde, Paruara, Pingo de ouro, Tatajuba e Tomazinha). Para tanto, raízes das diferentes cultivares foram desinfestadas com hipoclorito de sódio (3\%) e, em seguidas, lavadas com água destilada e secas em papel toalha. A inoculação do fungo foi feita em raízes de mandioca com e sem ferimento, usando dois discos de cultura por raiz. As raízes permaneceram em câmara úmida durante 72 horas. A avaliação foi realizada sete dias após a inoculação, observandose os sintomas decorrentes da ação de S. lignicola nas raízes. Em meio de BDA o fungo apresentou, inicialmente, colônia de cor branca, tornando-se escurecida após quatro dias de

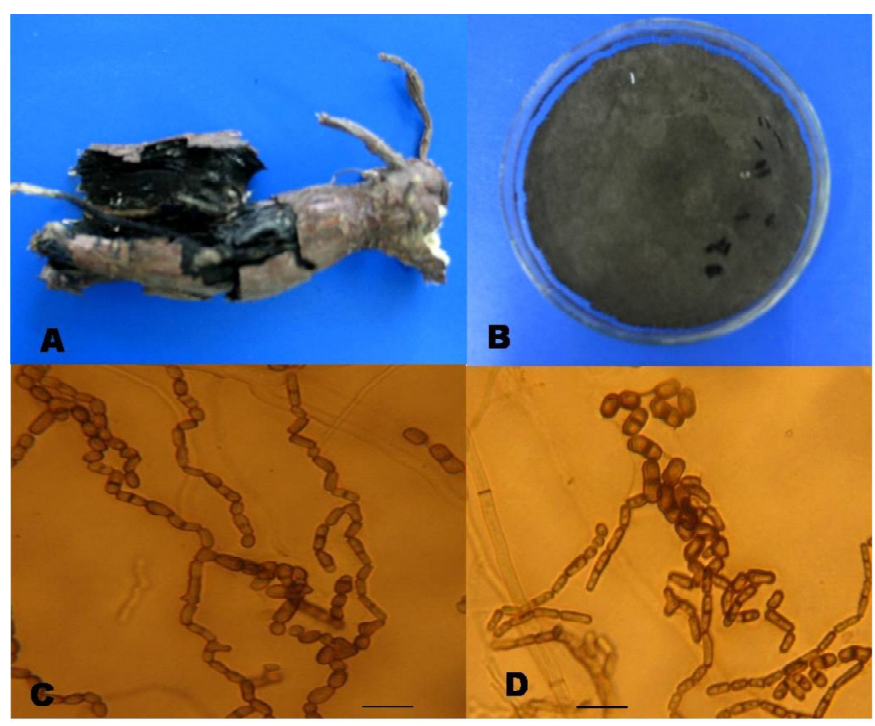

Figura 1. A. raízes de mandioca com sintomas de podridão negra causada por Scytalidium lignicola. B. cultura do patógeno em Batata-DextroseAgar (BDA). C e D. conídios em microscópio óptico (barra $=20 \mu \mathrm{m}$ ).

incubação (Figura 1B). As hifas apresentaram-se septadas, escuras, medindo em média 4,0-7,0 $\mu$ m de largura, e os conídios mostraram-se escuros, cilíndricos, esféricos ou sub-esfericos, lisos e a grande maioria sem septo, medindo 4,0-8,5 x 3,5-7,0 $\mu \mathrm{m}$ de comprimento e largura, respectivamente. De acordo com as características morfológicas observadas o agente causal foi identificado como Scytalidium lignicola Pesante (Figura 3C e 3D) conforme descrição de Ellis (1971 Dematiaceous Hyphomycetes. CMI). Todas as cultivares testadas apresentaram suscetibilidade ao fungo, com sintomas de podridão negra, tanto com e sem ferimento, após dois dias da inoculação. Este é o primeiro relato da ocorrência de $S$. lignicola causando podridão negra em raízes de mandioca no Maranhão, doença que pode se tornar importante para o Estado. O isolado fúngico foi encaminhado para a Coleção de Fungos Fitopatogênicos "Profa. Maria Menezes" da UFRPE. 


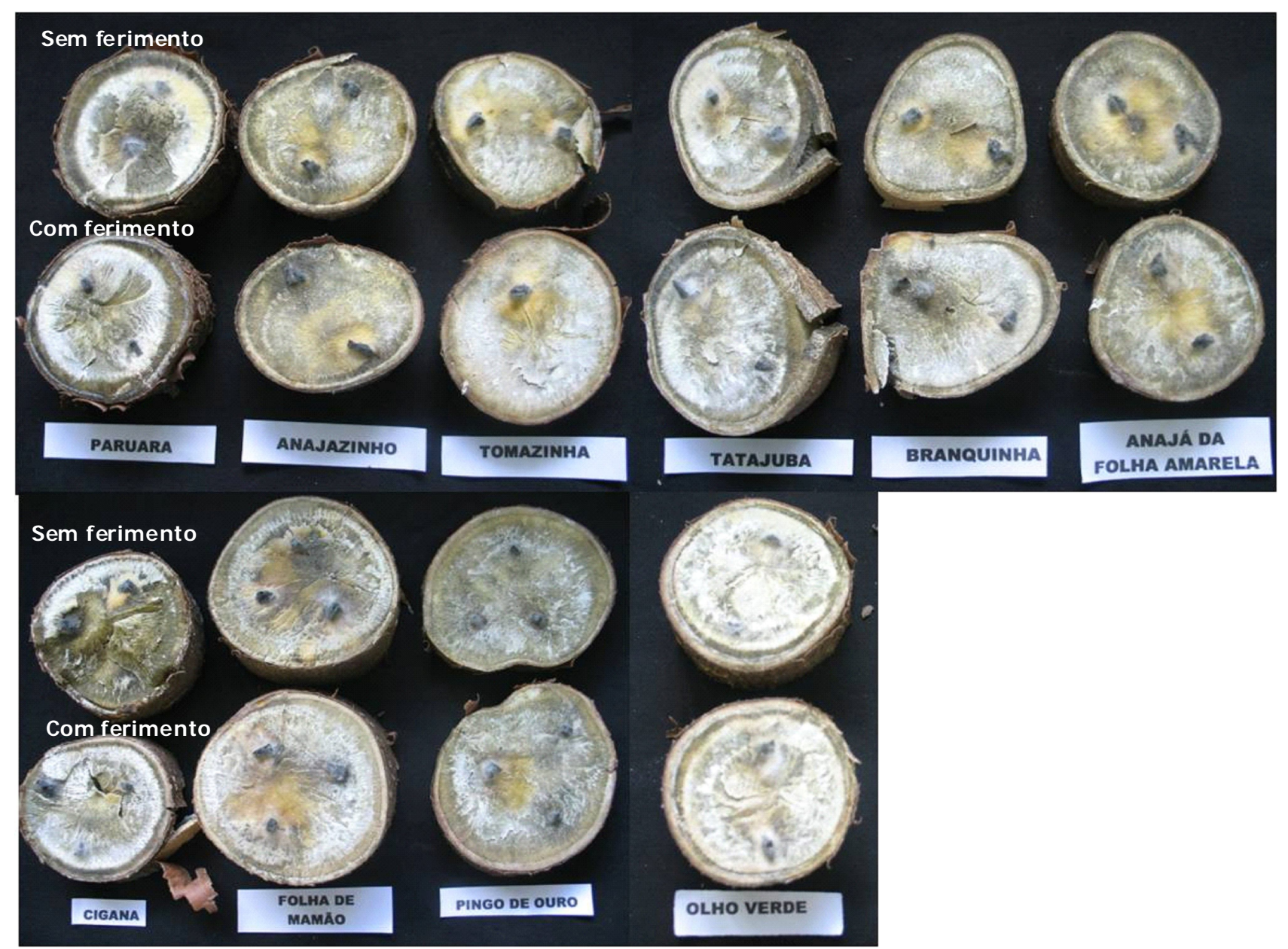

Figura 2. Reação de suscetibilidade à podridão negra causada por Scytalidium lignicola, em raízes de mandioca, de diferentes cultivares, inoculadas com e sem ferimentos. 